\title{
Optimization and Analysis of Cutting Tool Geometrical Parameters using Taguchi Method
}

\author{
OLODU, DD \\ Department of Production Engineering, University Of Benin, Benin City, Edo State, Nigeria. \\ E-mail: dickson.olodu@eng.uniben.edu Author Tel: +234-806-532-5363
}

\begin{abstract}
This study presents the finite element analysis of the influence of cutting tool geometrical parameters (nose radius, rake angle and clearance angle) on machining process evaluation indicators such as cutting force, temperature and thermal deformation of the tool using Taguchi method to statistically evaluate the signal-tonoise ratio. The values of the $F_{z}$ forces increased significantly as the nose radius increased. The increase in the nose radius leads to a higher $F_{z}$ force with approximate value of $360-400 N$. The values of $F_{y}$ forces were observed to have increased to about $140 \mathrm{~N}$ as the nose radius increased. Regarding the influence of nose radius on the temperature, it was observed that the highest temperature value was obtained for a nose radius of $0.8 \mathrm{~mm}$, while the lowest temperature value was obtained for a nose radius of $0.4 \mathrm{~mm}$
\end{abstract}

DOI: https://dx.doi.org/10.4314/jasem.v22i3.9

Copyright: Copyright (C) 2018 Olodu DD et al. This is an open access article distributed under the Creative Commons Attribution License (CCL), which permits unrestricted use, distribution, and reproduction in any medium, provided the original work is properly cited.

Dates: Received: 22 January 2018; Revised: 28 February: 2018; Accepted: 10 March 2018

Keywords: Cutting tool, Finite element, Machining process and Taguchi method.

The performance of the cutting process is influenced by the machining parameters and the geometrical parameters of the cutting tool. Due to the actual requirements of the cutting and cutting tools domain, tool manufacturers must continually optimize the geometric parameters of the cutting tool. In order to avoid high consumption of materials and tools as well as time and costs, researchers were involved on the cutting tool domain and propose new solution to optimize machining process. Zouhar and Piska (2017) investigated the cutting process simulation using cutting tools with different geometries both, for the rake angle and tool nose radius. Their result show that the increase in cutting forces were significantly influenced by increasing the rake angle of the tool, and on the other hand, increasing the nose radius of the tool leads to reduced forces. Pansare and Kavade (2016) optimized the cutting process parameters using the ANT colony algorithm in order to achieve a minimum surface roughness. Bassett et al.,(2012); Kountanya et al., (2016) studied the effect of tool edge geometry and cutting conditions on the chip morphology in orthogonal hard turning of $100 \mathrm{Cr} 6$ steel. Their study shows that the edge radius does not influence the geometrical parameters of the chip. Moreover cutting forces decreases as the cutting speed increases and the chip formation frequency increases linearly with cutting speed, while a negative rake angle increases the chip pitch (Kountanya et al., 2016). Mahapatra et al., (2014) studied the impact of the cutting speed, feed and depth of cut on the quality of the machined surface. They propose a prediction model for surface roughness and optimization of cutting parameters using genetic algorithms. Kurt and Şeker (2017) investigated the effect of chamfer angle of polycrystalline cubic boron nitride cutting tool on the cutting forces, and the tool stresses in finishing hard turning of AISI 52100 steel. The results obtained by them show that an angle of $20^{\circ}$ has a major influence on the cutting forces. Aruna and Dhanalksmi (2014) studied the optimization of cutting parameters in turning of Inconel 718 with response surface method. Thus, the parameters obtained by optimization were validated by experimental tests.

The objective of this study is to determine the optimum geometrical parameters of the cutting tool using both, finite element analysis and Taguchi method.

\section{MATERIALS AND METHODS}

Experimental Design: This study was used to optimize and analyze the influence of the nose radius, rake angle and clearance angle on the cutting forces $\left(\mathrm{F}_{\mathrm{y}}\right.$ and $\left.\mathrm{F}_{\mathrm{z}}\right)$, cutting zone temperature and thermal deformation of the tool. The study was realized using the following steps: 1 . Design plan of experiments; 2 . Finite element simulation of the cutting process in 
accordance with the designed plan of experiment; 3 . The calculation of signal to noise ratio; 4 . Identifying the optimal test.

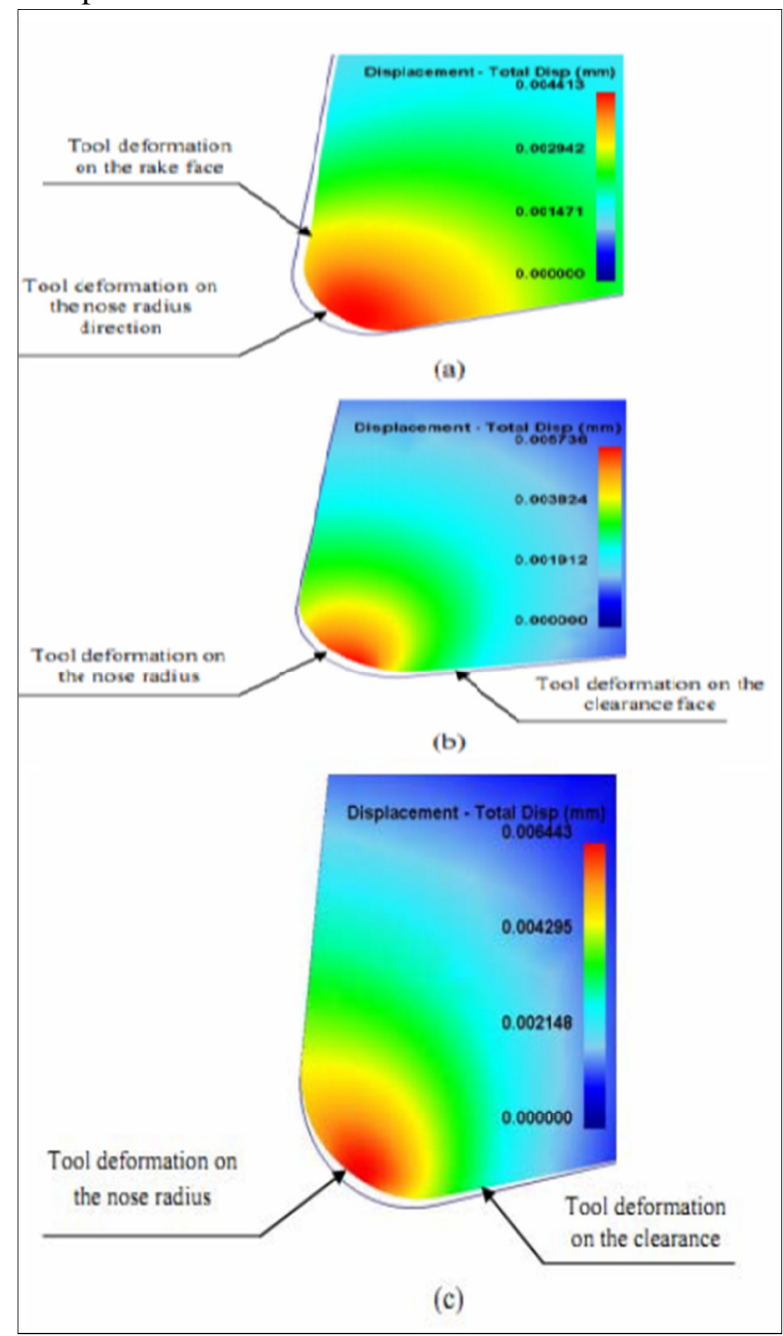

Fig 1: Thermal deformation of the cutting tool: (a) for $\mathrm{r} \beta=0.4 \mathrm{~mm}$; (b) for $\mathrm{r} \beta=0.8 \mathrm{~mm}$; (c) for $\mathrm{r} \beta=1.2 \mathrm{~mm}$.

Design Plan of Experiments: At this stage, an orthogonal experimental plan was developed and was varied on three levels, three geometric parameters of the tool: nose radius, rake angle and clearance angle. Three values were considered for the nose radius: $0.4 \mathrm{~mm}, 0.8 \mathrm{~mm}$ and $1.2 \mathrm{~mm}$. The following values were selected for rake angle: $6,7,8$, and for the clearance angle; 8, 10 and 12 .

Finite Element Simulation of the Cutting Process in Accordance with the Designed Plan of Experiment: For the finite element simulation of the cutting process, the Deform 2D software was used for the tests simulation. Machining parameters were kept constant so that the cutting speed was set to $280 \mathrm{~m} / \mathrm{min}$, the feed rate to $0.23 \mathrm{~mm} / \mathrm{rev}$ and depth of cut to $1.5 \mathrm{~mm}$. In order to study the influence of geometrical parameters on the cutting forces, temperatures and thermal deformations of the tool, the values of the nose radius, rake angle and clearance angle were considered variables. Regarding the choice of materials for tool and work piece, tungsten carbide was chosen for the tool and AISI 1045 carbon steel for the work piece.

The Calculation of Signal to Noise Ratio: The method of statistical analysis of signal to noise ratio developed by Taguchi method was applied in this study in order to identify the optimum combination of tool geometric parameters. This ratio was calculated using the formula in equation 1 (Julean, 2003).

$\frac{S}{N}=-10 * \log \left(S^{2}+0^{2}\right)[d B]$

where, $\mathrm{s}$ is the standard deviation of the measured values; $\overline{\mathrm{y}}$ - arithmetic mean of the measured values. Table 2 summarized the results for the signal to noise ratio.

\begin{tabular}{llll}
\multicolumn{3}{c}{ Table 1: Orthogonal Plan of Experiments } \\
\hline \multirow{2}{*}{ Test } & \multicolumn{3}{l}{ Input parameters } \\
\cline { 2 - 4 } & $\mathrm{r}_{\beta}$ & $\Gamma$ & $\mathrm{A}$ \\
& {$[\mathrm{mm}]$} & {$\left[{ }^{\circ}\right]$} & {$\left[{ }^{\circ}\right]$} \\
1 & 0.4 & 6 & 8 \\
2 & 0.4 & 7 & 10 \\
3 & 0.4 & 8 & 12 \\
4 & 0.8 & 6 & 10 \\
5 & 0.8 & 7 & 12 \\
6 & 0.8 & 8 & 8 \\
7 & 1.2 & 6 & 12 \\
8 & 1.2 & 7 & 8 \\
9 & 1.2 & 8 & 10 \\
\hline
\end{tabular}

Identifying the Optimal Test: The optimum ratio was identified by the maximum value calculated. From Table 2, the maximum value of $\mathrm{S} / \mathrm{N}$ ratio was obtained for the Test 3. Test 3 was the optimum combination of the nose radius, rake angle and clearance angle for this study. These values were shown in Table 3.

\section{RESULTS AND DISCUSSION}

Table 1 shows the orthogonal plan of experiment with the three levels of variation and the three factors of influence, Table 2 shows the output parameters and $\mathrm{S} / \mathrm{N}$ ratio values, Table 3 shows the optimal parameters of cutting tool geometry, Table 4 shows the means value of the output parameters respectively. Figure 1 shows the thermal deformation of the cutting tool: (a) for $r \beta=0.4 \mathrm{~mm}$; (b) for $\mathrm{r} \beta=0.8 \mathrm{~mm}$; (c) for $\mathrm{r} \beta=1.2 \mathrm{~mm}$, Figure 2 shows the variation of the cutting forces with rake angle, Figure 3 shows the variation of the thermal deformation with 
rake angle, Figure 4 shows the variation of the cutting forces with clearance angle, Figure 5 shows the variation of the temperature with clearance angle and Figure 6 shows the variation of the thermal deformation with clearance angle.

Table 2: Output Parameters and S/N Ratio Values

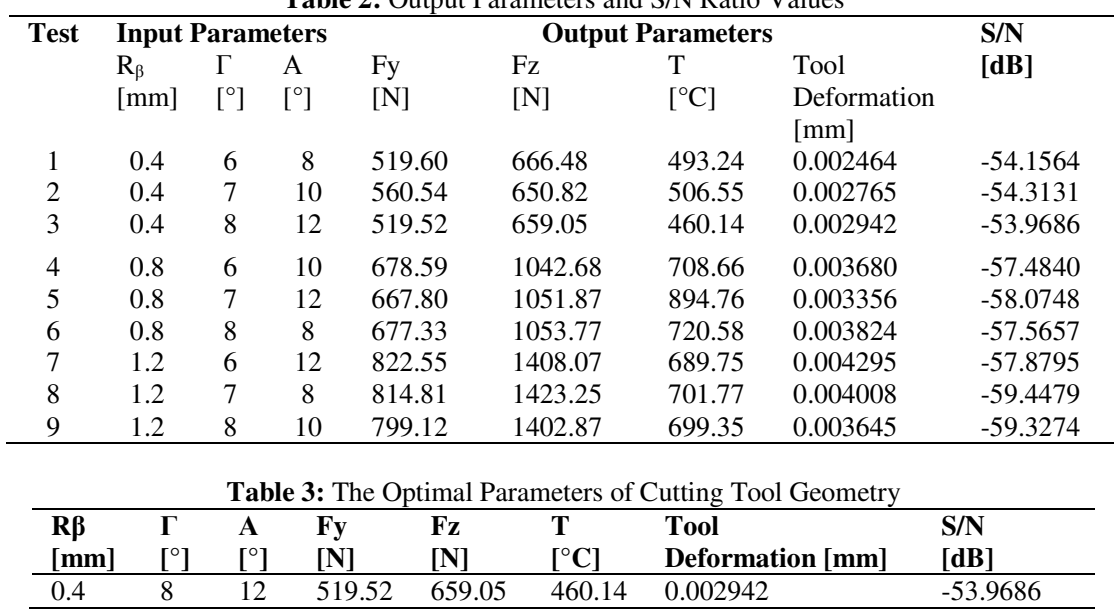

Table 4: Mean Value of the Output Parameters

\begin{tabular}{cccccc}
\hline $\begin{array}{l}\text { Geometric Parameters } \\
\text { of the Tool }\end{array}$ & $\begin{array}{c}\mathbf{F}_{\mathbf{y}} \\
{[\mathbf{N}]}\end{array}$ & $\begin{array}{c}\mathbf{F}_{\mathbf{z}} \\
{[\mathbf{N}]}\end{array}$ & $\begin{array}{c}\mathbf{T} \\
{\left[{ }^{\circ} \mathbf{C}\right]}\end{array}$ & $\begin{array}{c}\text { Tool Deformation } \\
{[\mathbf{m m}]}\end{array}$ \\
\hline $\mathrm{R}_{\beta}$ & 0.4 & 533.21 & 658.79 & 486.64 & 0.0027236 \\
{$[\mathrm{~mm}]$} & 0.8 & 674.57 & 1049.44 & 774.66 & 0.0036200 \\
& 1.2 & 812.16 & 1411.40 & 696.95 & 0.0039826 \\
$\Gamma$ & 6 & 673.58 & 1039.07 & 630.55 & 0.0033763 \\
{$\left[{ }^{\circ}\right]$} & 7 & 681.05 & 1041.98 & 701.03 & 0.0034796 \\
& 8 & 665.32 & 1038.56 & 626.69 & 0.0034703 \\
$\mathrm{~A}$ & 8 & 670.58 & 1047.83 & 638.53 & 0.0034320 \\
{$\left[{ }^{\circ}\right]$} & 10 & 679.42 & 1032.12 & 469.34 & 0.0033633 \\
& 12 & 669.96 & 1039.67 & 681.55 & 0.0035310 \\
\hline
\end{tabular}

Influence of the Nose Radius: The values of the $\mathrm{F}_{\mathrm{z}}$ forces increased significantly as the nose radius increased (Table 4). It was observed that increasing the nose radius lead to a higher $F_{z}$ force with approximately $360-400 \mathrm{~N}$. The value of $\mathrm{F}_{\mathrm{y}}$ force increased with about $140 \mathrm{~N}$ as the nose radius increased. Regarding the influence of nose radius on the temperature, it was observed that the highest and the lowest temperature value were obtained at a nose radius of $0.8 \mathrm{~mm}$ and $0.4 \mathrm{~mm}$ respectively (Table 4 ).

Moreover, the thermal deformation of the cutting tool increased as the nose radius increased. It is important to note that for a nose radius value of $0.4 \mathrm{~mm}$, cutting tool deform on the radius and rake face direction, and for the other two values, the deformation took place on the radius and clearance face direction (Figure 1).

Influence of the Rake Angle: From the study of the influence of rake angle on the forces (Figure 2), it was observed that these values were kept approximately constant, and the lower force value was obtained at rake angle of $8^{\circ}$. Regarding to the temperature variation and thermal deformation with the rake angle, the results show that the highest values were recorded for an angle of $7^{\circ}$ (Figure 3 and 4).

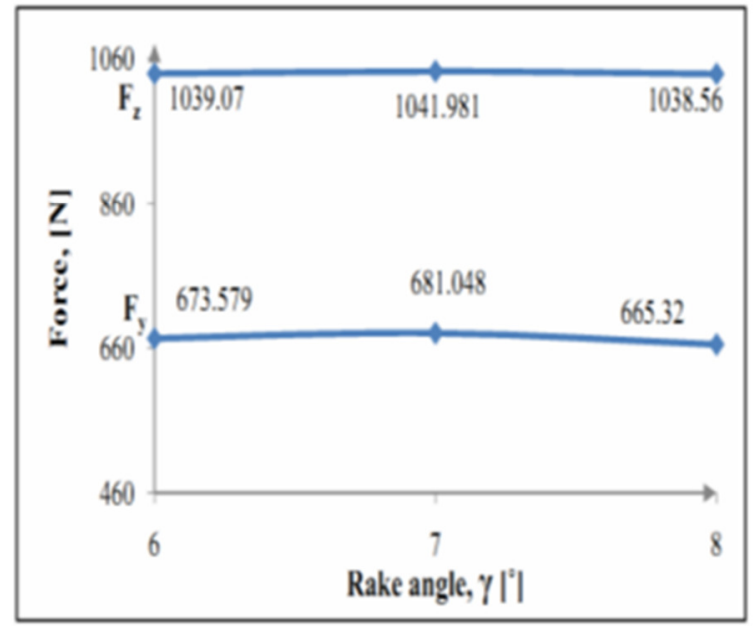

Fig 2: Variation of the Cutting Forces with Rake Angle

Influence of the Clearance Angle: The value of the forces were considered to be approximately constant, and in the case of temperature there was a reduction of $170^{\circ}-200^{\circ}$ for a rake angle value of $10^{\circ}$ compared 
with $8^{\circ}$ and $12^{\circ}$ (Figure 4 and 5). From Figure 6, it was observed that the thermal deformation of the tool also decreased by $10^{\circ}$ rake angle value.

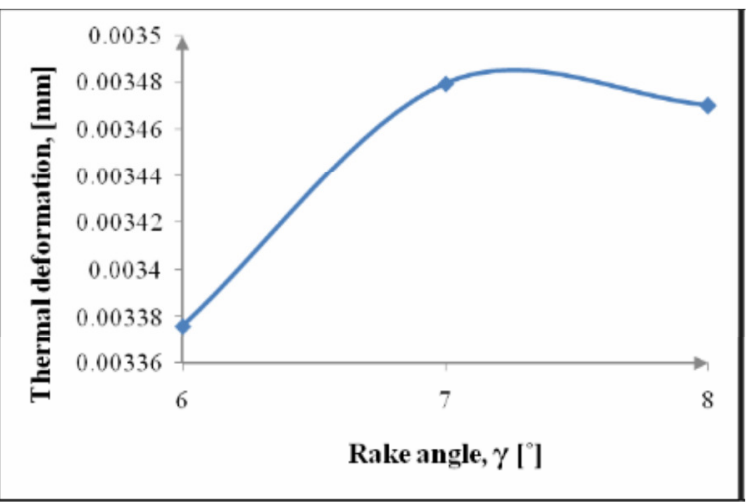

Fig 3: Variation of the Thermal Deformation with Rake Angle

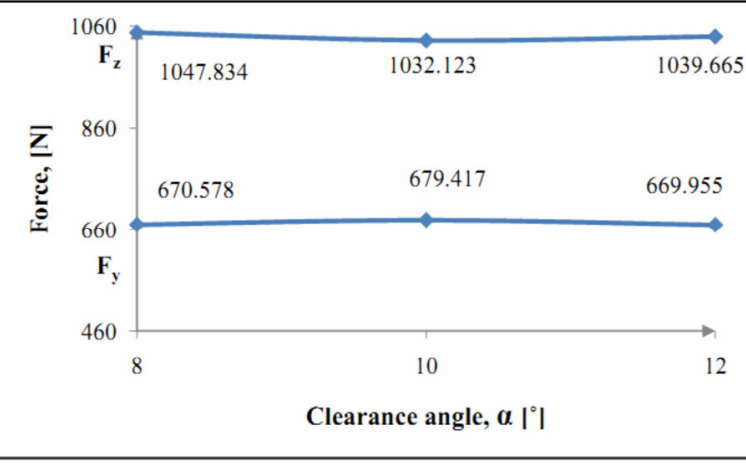

Fig 4: Variation of the Cutting Forces with Clearance Angle

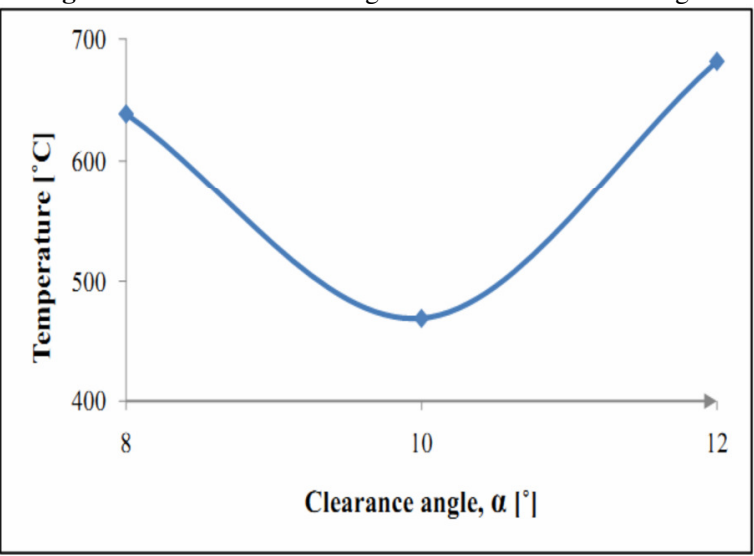

Fig 5: Variation of the temperature with clearance angle

Conclusion: The study of the influence of tool geometric parameters on the cutting forces, temperature and thermal deformation of the tool were investigated. The study involved both finite element analysis and optimization of cutting tool geometric parameters by Taguchi method. Thus, force values increased as the nose radius increased, the lowest force and temperature value were obtained for a nose radius of $0.4 \mathrm{~mm}$. Thermal deformation increased as the nose radius increased. The rake angle and clearance angle value had a small influence on the cutting forces.

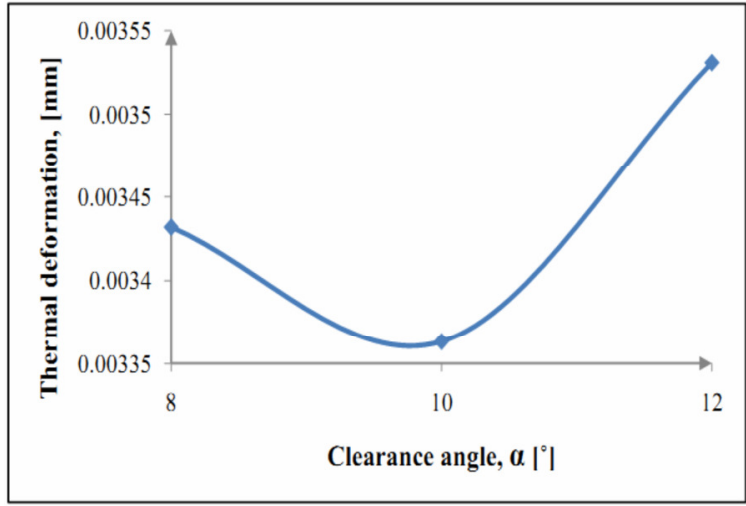

Fig 6: Variation of the thermal deformation with clearance angle.

\section{REFERENCES}

Aruna, M; Dhanalksmi, V (2014). Design optimization of cutting parameters when turning Inconel 718 with Cermet Inserts. World Academy of Science, Engineering and Technology 61, pp 952-955.

Bassett, E; Köhler, J; Denkena, B (2012). On the Honed Cutting Edge and its Side Effects During Orthogonal Turning Operations of AISI 1045 with Coated WC-Co Inserts. CIRP Journal of Manufacturing Science and Technology 5, pp 108-126.

Julean, D. (2003). Experimental Cutting. U.T. PRES, ISBN 973-662-011-5, Cluj-Napoca

Kountanya, R; Al-Zkeri, I; Altan, T (2016). Effect of Tool Edge Geometry and Cutting Conditions on Experimental and Simulated Chip Morphology in Orthogonal Hard Turning of $100 \mathrm{Cr}_{6}$ Steel. Journal of Materials Processing Technology 209, pp 5068-5076

Kurt, A; Şeker, U (2017). The Effect of Chamfer Angle of Polycrystalline Cubic Boron Nitride Cutting Tool on the Cutting Forces and the Tool Stresses in Finishing Hard Turning of AISI 52100 steel. Materials and Design 26, pp 351-356.

Mahapatra, S; Patnaik, A; Patnaik, P (2014). Parametric Analysis and Optimization of Cutting Parameters for Turning Operation Based on Taguchi Method. Proceedings of the International Conference on Global Manufacturing and Innovation - July 27-29, pp 1-8.

Pansare, VB; Kavade, MV (2016). Optimization of Cutting Parameters in Multipass Turning Operation using ANT Colony Algorithm. International Journal of Engineering Science and Advanced Technology, Vol.2, Issue 4, pp 955-960.

Zouhar, J; Piska, M (2017). Modelling the Orthogonal Machining Process using Cutting Tools with Different Geometry. MM Science Journal, pp48-52. 